Abstract 0-079 Table 1 Demographics of Study Population $(\mathrm{n}=$ 30)

\begin{tabular}{ll}
\hline GA at time of study & $31.7(30.7,33.5)$ \\
Postnatal age in days & $43(23.5,53.5)$ \\
Weight in kg at time of study & $1.4(1.1,1.6)$ \\
Insignificant PDA/PFO & $6 / 8$ \\
Surfactant (given at birth / 2nd dose) & $25 / 7$ \\
Ventilated before study & 27 \\
Bubble CPAP /ventilator CPAP & $24 / 6$ \\
CPAP requirement (5/6/7 cm $\left.\mathrm{H}_{2} \mathrm{O}\right)$ ) & $13 / 7 / 10$ \\
$\mathrm{O}_{2}$ requirement (\%) & $30(25,30)$ \\
Capillary gas: $\mathrm{pH}$ & $7.35(7.34,7.39)$ \\
Capillary gas: $\mathrm{pCO}_{2}$ (mmHg) & $53(47,55)$ \\
Capillary gas: $\mathrm{HCO}_{3}^{-}$(mmol/I) & $29(25,34)$ \\
Capillary gas: base excess & $2.6(-0.4,4.8)$ \\
Respiratory support at 36 weeks GA & 12 \\
$\mathrm{O}_{2}$ requirement at 36 weeks GA & 25 \\
Values given as median (IQR) or absolute numbers. &
\end{tabular}

Abstract 0-079 Table 2 Haemodynamic parameters on three nCPAP levels

\begin{tabular}{lllll}
\hline & $4 \mathrm{~cm} \mathrm{H}_{2} \mathrm{O}$ & $6 \mathrm{~cm} \mathrm{H} \mathrm{H}_{2} \mathrm{O}$ & $8 \mathrm{~cm} \mathrm{H} \mathrm{H}_{2}$ & $\mathrm{p}$ \\
RVO (ml/kg/min) & $411 \pm 110$ & $418 \pm 94$ & $414 \pm 93$ & 0.98 \\
LVO (ml/kg/min) & $407 \pm 121$ & $405 \pm 140$ & $403 \pm 123$ & 0.96 \\
SVC flow (ml/kg/min) & $157 \pm 53$ & $149 \pm 4$ & $155 \pm 42$ & 0.58 \\
LPA flow (ml/kg/min) & $136 \pm 57$ & $142 \pm 61$ & $136 \pm 53$ & 0.45 \\
TAPSE (mm) & $7.9 \pm 1.8$ & $8.1 \pm 1.5$ & $8.0 \pm 1.2$ & 0.58 \\
BP systolic (mmHg) & $73 \pm 9$ & $71 \pm 9$ & $74 \pm 13$ & 0.34 \\
BP mean (mmHg) & $52 \pm 9$ & $53 \pm 8$ & $55 \pm 11$ & 0.28 \\
BP diastolic (mmHg) & $40 \pm 1$ & $43 \pm 1$ & $46 \pm 12$ & 0.11 \\
HR (beats/min) & $163 \pm 13$ & $164 \pm 13$ & $162 \pm 13$ & 0.62 \\
\hline
\end{tabular}

Results Thirty infants with a median (IQR) gestational age of 25.9 (25.6-26.8) weeks and a birth weight of $0.78(0.66-0.94)$ $\mathrm{kg}$ were studied at a median age of 43 (24-53) days. There were no significant differences in any cardiovascular parameters at different levels of nCPAP.

Discussion We conclude that nCPAP levels between 4 and $8 \mathrm{~cm}$ $\mathrm{H}_{2} \mathrm{O}$ did not have an effect on $\mathrm{CO}$ in our study population of stable preterm infants with evolving chronic lung disease.

\section{Nosocomial Infections in the ICU}

\section{0-080 ELEVATED SOLUBLE THROMBOMODULIN IS ASSOCIATED WITH INCREASED MORTALITY AMONG CHILDREN WITH INDIRECT ACUTE RESPIRATORY DISTRESS SYNDROME (ARDS)}

${ }^{1}$ B Orwoll, ${ }^{1} \mathrm{~A}$ Spicer, ${ }^{2} \mathrm{RG}$ Khemani, ${ }^{3}$ J Boriosi, ${ }^{1} \mathrm{E}$ Colglazier, ${ }^{1} \mathrm{I}$ Damm, ${ }^{4} \mathrm{HR}$ Flori, ${ }^{5} \mathrm{CS}$ Calfee, ${ }^{5}$ M Matthay, ${ }^{1}$ A Sapru. ${ }^{1}$ Pediatric Critical Care, University of California San Francisco, San Francisco, USA; ${ }^{2}$ Pediatric Critical Care, Children's Hospital Los Angeles, Los Angeles, USA; ${ }^{3}$ Pediatric Critical Care, University of Wisconsin, Madison, USA; ${ }^{4}$ Pediatric Critical Care, Children's Hospital and Research Center, Oakland, USA; ${ }^{5}$ Medicine and Anesthesia, University of California San Francisco, San Francisco, USA

10.1136/archdischild-2014-307384.147
Abstract 0-080 Table 1 Cohort characteristics comparing Direct and Indirect Injury-related ARDS

\begin{tabular}{|l|l|l|}
\hline & Direct $(\mathrm{n}=133)$ & Indirect $(\mathrm{n}=91)$ \\
\hline Age $(\mathrm{y})$ & 6.2 & 7.5 \\
\hline Male (\%) & 58 & 51 \\
\hline White (\%) & 62 & 66 \\
\hline Pneumonia & 124 & 0 \\
\hline Aspiration & 9 & 0 \\
\hline Sepsis & 0 & 46 \\
\hline Trauma & 0 & 13 \\
\hline Multiple Transfusions and others & 0 & 32 \\
\hline Vasopressor Use (p=0.001) & 33 & 55 \\
\hline PRISM II (SD) & $16(10)$ & $13(9)$ \\
\hline PELOD (SD) & $19(12)$ & $21(14)$ \\
\hline Mortality (\%) & 12 & 15 \\
\hline & & \\
\hline
\end{tabular}

ARDS Mortality and PELOD Score by Tertile of sTM Levels

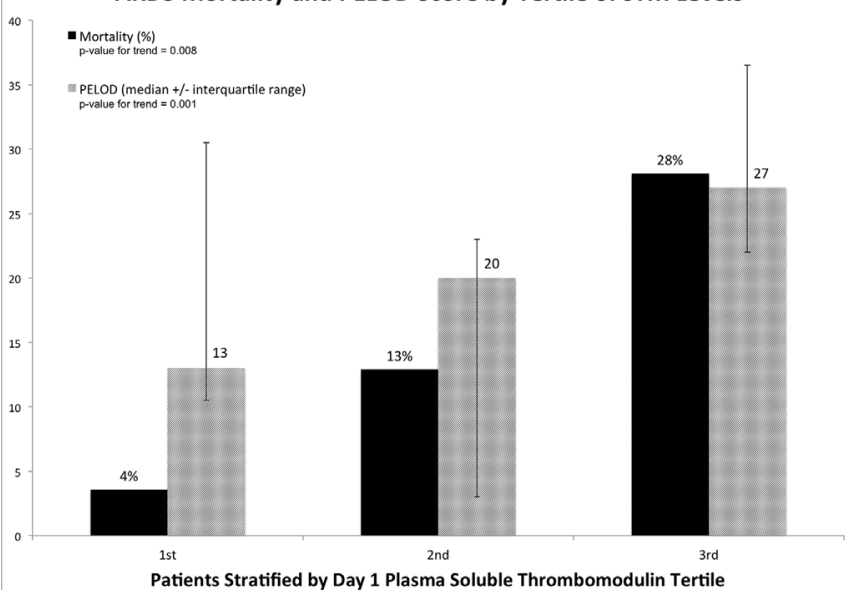

Abstract 0-080 Figure 1 ARDS Mortality and PELOD Score by Tertile of sTM Levels

Background Inflammation and endothelial damage accelerate cleavage of endothelium bound Thrombomodulin (TM). Elevated soluble TM (sTM) in plasma is associated with adverse outcomes in sepsis and DIC in adults, but this has not been studied among children with ARDS.

Objective Test the relationship of plasma sTM with clinical outcomes in paediatric ARDS.

Design/methods We measured STM in plasma collected within $24 \mathrm{~h}$ of onset of ARDS (diagnosed by Berlin criteria) in an ongoing multi-centre observational cohort. We used non-parametric Mann-Whitney and trend tests, and regression models.

Results Baseline characteristics of study population are shown in Table. Among children with indirect lung injury, mean sTM levels were higher in non-survivors [241 ng/mL (102-134)] compared to survivors $[118 \mathrm{ng} / \mathrm{mL} \quad(107-374)] \quad(\mathrm{p}=0.004)$. Mortality and Paediatric Logistic Organ Dysfunction (PELOD) score increased stepwise by tertile of plasma sTM (figure). On logistic regression, the odds of death increased by 4.5 for every $\log$ increase in plasma sTM and the association was independent of age, race, gender and severity of illness. No such relationship existed for direct ARDS.

Conclusions Higher plasma sTM is associated with increased mortality and organ failure in children with indirect ARDS. This supports the importance of endothelial injury and TM in pathobiology of indirect ARDS and suggests that early elevation in plasma sTM is an independent risk factor for mortality. 